\title{
Articulator and Facebow: Review of Literature and History of Articulators
}

Batra $\boldsymbol{P}^{1}$

\begin{abstract}
Articulators and facebows are the integral part of any branch of prosthodontics. We all have seen, the constant innovation, expansion and evolution of these two important instruments through the years. The core aim of this article is to bring in light, the way these instruments were used around more than five decades back till recent times as well as theories and principles related to their uses are also changing as the passes. This review has shown conclusions of many researchers on so many concepts like superiority of arcon articulator over non-arcon articulators, survey of their use in dental school/ colleges, various techniques of recording jaw movements like transographic, stereographic, axiographic, digital \& more and importance of terminal hinge axis. Efforts were made and still going on to record the accurate jaw movements in order to make a prosthesis which functions harmoniously and also preserve the remaining tissues, which is a big aim of prosthodontics.
\end{abstract}

Keywords: Arcon articulator, Non arcon articulator, Transography, Stereography, Terminal hinge axis

${ }^{1}$ Reader

Department of Prosthodontics

Inderprastha Dental College

Sahibabad, Ghaziabad, U.P (INDIA)

\section{Contact Author \\ Dr. Puneet Batra drpuneetbatra111@gmail.com}

J Oral Health Comm Dent 2013;7(1)57-63

\section{INTRODUCTION ARTICULATOR: REVIEW OF LITERATURE}

$\Lambda$ rticulators are instruments that at tempt to reproduce the range of and mandibular casts are attached to the articulators so that functional and parafunctional contact relation between the teeth can be studied. It is often said "patient's mouth is the best articulator". The primary function of articulator is to act as a patient (1)

Articulator is defined as, a mechanical device that represents the temporomandibular joints and jaw members to which maxillary and mandibular casts may be attached to simulate jaw movement (2) (GPT-7).

Jerome M. Schwitzer(1956) (3)developed the transograph and transographic articulators.

Heinz O Beck (1959) (4) conducted study on the clinical evaluation of the arcon concepts of articulation and concluded that no definite superiority could be noted in the clinical evaluation of complete dentures constructed on the arcon over the condylar type of instruments.

Thomas E. J. Shanahan (1959) (5) studied the mandibular and articulator movements with the purpose to compare the opening and closing movements of the mandible with the opening and closing movements of hinge axis articulator. He concluded that the normal opening and closing movements of the mandible do not conicide with the opening and closing movements of a hinge-axis articulator.

Pruden WH(1960) (6) described the role of study casts in diagnosis and treatment planning and mentioned that "it is mandatory that diagnostic casts be placed in an articulator in approximately the same relationship to the temporomandibular joints as exists in patient".

Heinz O. Beck (1960) (7) gave the following guidelines for selection of an articulator for complete denture construction: A centric relation record, selected eccentric records of the protruded, right and left lateral maxillo-mandibular positions for 
adjusting instruments which are used as a tripod, hinge axis record, axis-orbital reference planeand condylar guides should be attached to the upper member of articulators.

Thomas E. J. Shanahan (1962) (8) conducted a geometric study on the opening and closing cyclic mandibular movements and concluded "The mandible rotates about an axis which translate" and concluded that mandible does not normally open and close on an axis and that the mandibular axis is a myth.

A.A. Grant (1963) (9) demonstrated the method by which the elevation of incisal guide pin associated with attachment of casts to the articulator can be prevented.

Lawrence A. Weinberg (1963) (10) described the concept of fully adjustable articulators.

Lawrence A. Weinberg (1963) (11) published an article "Arcon principle in the condylar mechanism of adjustable articulators" and concluded that both the arcon and condylar instruments produce the same motion because condylar guidance is the result of the interaction of a condylar ball on an inclined plane. The only change is in the numbers used to record the inclination.

Lawrence A. Weinberg (1963) (12) suggested that a more adjustable instrument than Hanau model $\mathrm{H}$ articulator would seem to be indicated for fixed restorative prosthesis in order to reduce the degree of occlusal correction necessary to harmonize biologic movement with the occlusion produced on the articulator.

Robert L. Lee (1969) (13) demonstrated the programming of articulator by engraving jaw movements in solid plastic.

Lundeen HC, Wirth CG (1973) (14) conducted a study to test the reliability and reproducibility of a method of three dimensional tracing of mandibular movements in plastic blocks. They also gave average anatomic value of $1.0 \mathrm{~mm}$ for immediate side shift.
Bell LJ, Matich JA (1977) (15) conducted a study on the acceptability of lateral records by the whip-mix articulators and recommended the interocclusal records for setting the posterior control of the articulators.

Donald L. Mitchell (1978) (16) published in his article "Articulators through the years" stated that articulators introduced since 1940 till today' fully adjustable articulator should be preserved. All of them are either in the historical collection of the national naval dental center or in actual use at that institution.

Kenneth H. Swanson (1979) (17)described a method of recording mandibular movements in a stereographic recoding and registering these movements by molding the controls in an articulator.

Dale E. Smith (1985) (18) conducted a survey to determine the type of articulators used in teaching fixed and removable prosthodontics in the 59 United states dental schools and concluded that of the 81 articulators used in fixed and removable prosthodontics $65(76.5 \%)$ were of the arcon design and most common articulators used for removable prosthodontics were whipmix(16) and in fixed prosthodontics were the denar mark 11 (11).

Tamaki K et al(1997) (19) studied the accuracy of reproduction of excursive tooth contacts in an articulator with computerized axiography and concluded that no method used to programme an articulator to reproduce eccentric jaw movements is without error.

Korda B, Gartner C et al (2002) (20) gave the concept and development of virtual articulator in dentistry. Virtual reality enables new perspectives in visualizing complex relationships in diagnosis of occlusion and function. The new virtual articulator provides interesting modules for presenting and analyzing the dynamic contacts of the occlusal surfaces of the maxilla and mandible and the relation to condylar movement.
FACEBOW: REVIEW OF LITERATURE Stansberry (1928) (21) was dubious about the value of facebow and and adjustable articulators. He thought that since an opening movement about the hinge axis took the teeth out of contact the use of these instruments was ineffective except for the arrangement of the teeth in centric occlusion.

Mclean (1937) (22) stated that the hinge portion of the joint is the great equalizer for disharmonies between the gnathodynamic factors of occlusion. When occlusion is synthesized on articulator without accurate hinge axis orientation, there may be minor cuspal conflicts, which must be removed by selective spot grinding.

Kurth LE, Feinstein IK(1951) (23) with aid of articulator and working model, demonstrated that more than one point may serve as a hinge axis and concluded that an infinite number of points exist which may serve as hinge points.

Craddock and symmons (1952) (24),considered that the accurate determination of the hinge axis was only of academic interest since it would never be found to be more than a few millimeters distance form the assumed center in the condyle itself.

Sloane(1952) (25) stated "the mandibular axis is not a theoretical assumption, but a definite demonstrable biomechanical fact. It is an axis upon which the mandible rotates in an opening and closing function when comfortably, not forcibly retruded.

Bandrup-morgsen (1953) (26), discussed the theory and history of face bows. $\mathrm{He}$ quoted the work of Beyron who had demonstrated that the axis of movement of the mandible did not always pass through the centers of the condyles. They concluded that complicated forms of registration were rarely necessary for practical work.

Lazarri (1955) (27) gave application of Hanau model"c" facebow.

Sicher(1956) (28) stated "the hinge position or terminal hinge position is that posi- 


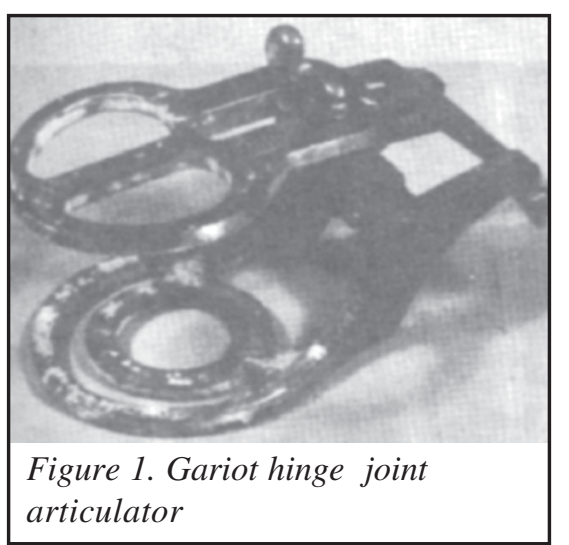

tion of the mandible from which or in which pure hinge movement of a variable wide range is possible"

Robert.G.Schallhorn (1957) (29), studying the arbitrary center and kinematic center of the mandibular condyle for face bow mountings. He concluded that using the arbitrary axis for face bow mountings on a semiadjustable articulator is justified. He said that, in over $95 \%$ of the subjects the kinematic center lies within a radius of 5 $\mathrm{mm}$ from the arbitrary center.

Brekke (1959) (30) in reference to a single intercondylar transverse axis stated "unfortunately this optimum condition does not prevail in mandibular apparatus, which is symmetric in shape and size, and has its condyloid process joined at the symphysis, with no connection directly at the condyles. The assumption of a single intercondylar transverse axis is, therefore open to serious question".

Christiansen RL(1959) (31) studied the rationale of facebow in maxillary cast mounting and concluded that it is advantageous to simulate on the articulator the anatomic relationship of the residual ridges to the condyles for more harmoniously occluding complete dentures.

Weinberg (1961) (32) evaluated the facebow mounting and stated that a deviations from the hinge axis of $5 \mathrm{~mm}$ will result in an anteroposterior displacement error of $0.2 \mathrm{~mm}$ at the second molar.

Lucia VO (1964) (33) described the technique for recording centric relation with help of anterior programming device.

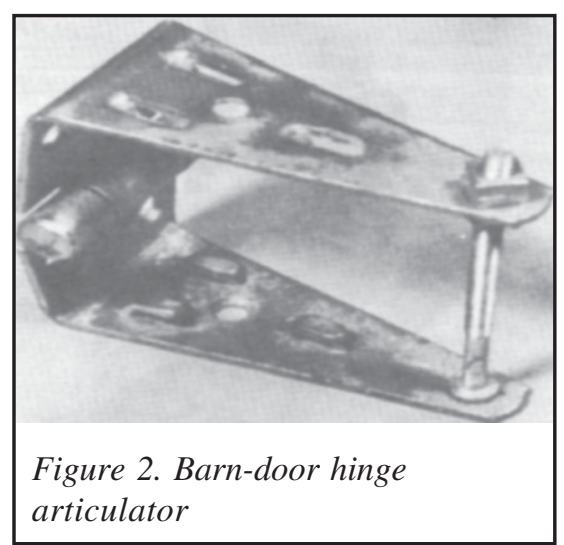

Teteruck and Lundeen (1966) (34), evaluated the accuracy of the earpiece face bow and concluded that only $33 \%$ of the conventional axis locations were within $6 \mathrm{~mm}$ of true hinge axis as compared to $56.4 \%$ located by ear face-bow. They also recommended the use of earpiece bow for its accuracy, speed of handling, and simplicity of orienting the maxillary cast.

Trapazazano, Lazzari (1967) (35) concluded that, since multiple condylar hinge axis points were located, the high degree of infallibility attributed to hinge axis points may be seriously questioned.

Thorp, Smith, and Nicholis (1978) (36), evaluated the use of face bow in complete denture occlusion. Their study revealed very small differences between a hinge axis face bow Hanau 132-sm face bow, and whip mix ear-bow.

Neol D.Wilkie (1979) (37) analyzed and discussed five commonly used anterior points of reference for a face bow transfer. He said that not utilizing a third point of reference may result in an unnatural appearance in the final prosthesis and even damage to the supporting tissue. He suggests the use of the axis-oribitale plane because of the ease of making and locating orbitale and therefore the concept is easy to teach and understand.

Stade E et al(1982) (38) evaluated esthetic consideration in the use of facebow.

Palik J.F et al(1985) (39) concluded in his study on the accuracy of earpiece facebow that regardless of any arbitrary position

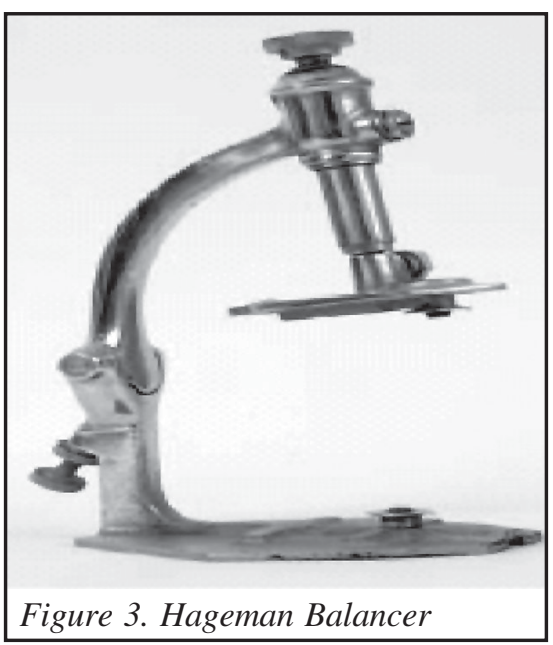

chosen, a minimum error of $5 \mathrm{~mm}$ from the axis can be expected.

\section{HISTORY OF ARTICULATORS Gariot hinge joint articulators (Figure 1)}

J.B Gariot reportedly designed the first hinge articulators in 1805. Gariot's articulator consisted of two metal frames to which the cast could be attached.It is nonadjustible articulator. A simple hinge to join them and a set screw in the posterior of instrument to hold the frames in a fixed vertical position (40).

\section{Barn-door hinge articulator (Figure 2)}

It is non-adjustable articulator with an anterior vertical stop. It will accept a centric relation $\operatorname{record}(40)$.

\section{Hageman balancer (Figure 3)}

It is a non-adjustable articulator which opens and closes on a hinge(40).

\section{Bonwill articulator in 1858 (Figure 4)}

It is non-adjustable and imitates the movement of mandible in eccentric position(40).

\section{Grittman articulator in 1899 (Figure 5)}

It is non adjustable articulator. The condyles are on the lower member of the articulator and the path are inclined $15^{\circ}$.The casts are mounted on this instrument according to bonwill's triangle, which is a four inch equilateral triangle from condyle 


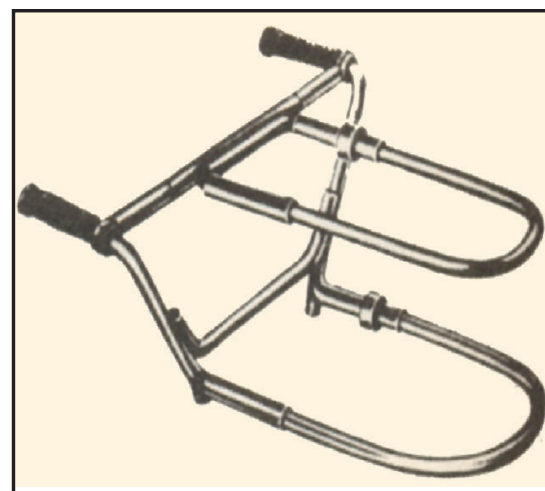

Figure 4. Bonwill articulator

to condyle and to the lower central incisor contact point(41).

\section{Acme articulators (1906) (Figure \\ 6)}

It is a semi adjustable articulator. It is available in three models to accommodate three ranges of intercondylar distance(40).

\section{Gysi simplex adaptable articulator in 1908 (Figure 7)}

It is a semi-adjustable articulator and advanced instrument at that time, uses extraoral tracing(42).

\section{Gysi simplex articulator in 1914 (Figure 8)}

Designed by Alfred Gysi of zurich in 1914. It is non-adjustable and mean value articulator. The condyles are on the lower member, the condylar paths are inclined at $30^{\circ}$ and the incisal guidance is fixed at $60^{\circ}$.

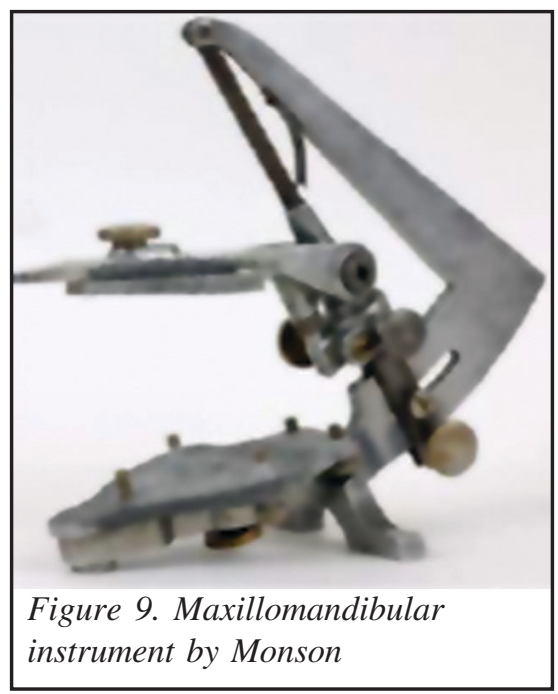

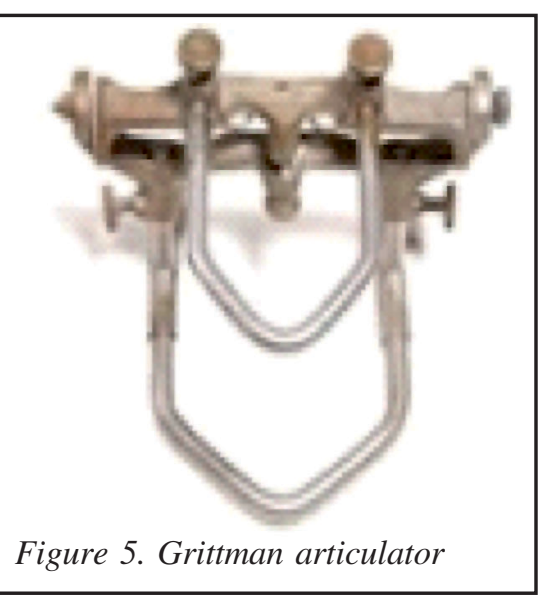

\section{Monson articulator (Figure 9)}

Designed by Monson in 1918 and is typical of this class. Monson's instrument is based on spheric theory of occlusion, in which each cusp and incisal edge conforms to a segment of the surface of a sphere eight inches in diameter with its center at the glabella (41) (Figure 10).It is a non adjustable articulator. The upper member of the instrument moves anteroposteriorly and mediolaterally, according to Monson's spheric theory.

\section{The Stephan articulator (modified)} (Figure 11)

The Stephan articulator as modified in 1940 is a simple hinge joint articulator that has a fixed condylar path of 30 degrees and

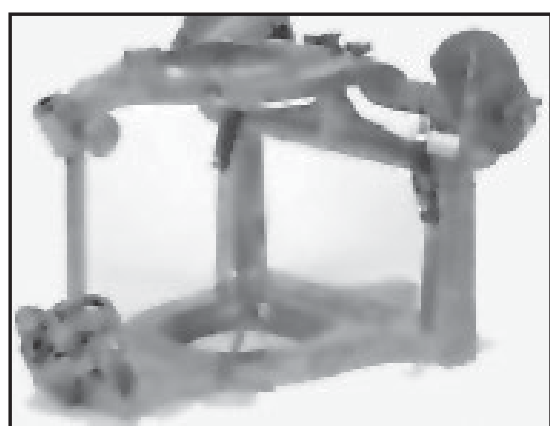

Figure 7. Gysi simplex adaptable articulator

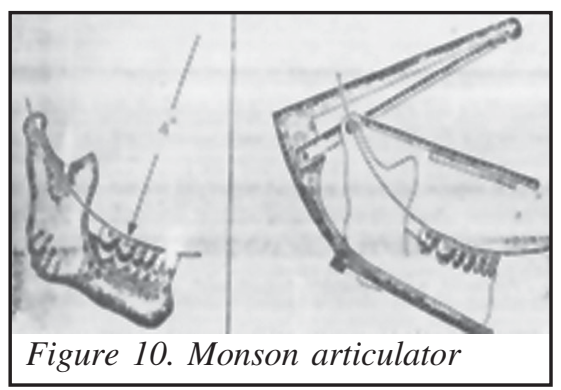

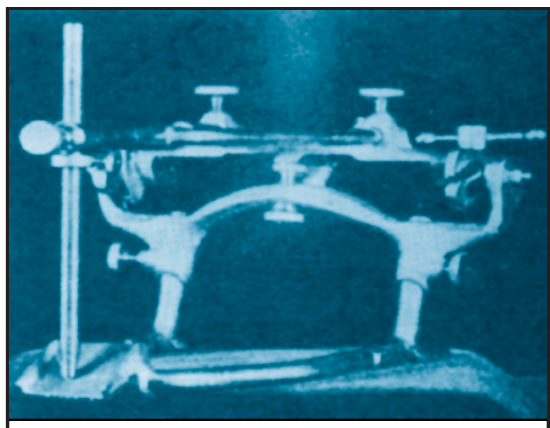

Figure 6. Acme articulator

is non adjustable. It has an adjustable set screw in the posterior region holds the upper and lower members in a fixed vertical position(43).

\section{The Stephan articulator model p (Figure 12)}

The additional features of the Stephan articulator model $\mathrm{p}$ are an incisal pin and a vertical height adjustment.

\section{The Johnson-Oglesby and Moyer articulators}

The Johnson - Oglesby articulator (Figure 13) and the Moyer articulator (Figure 14)
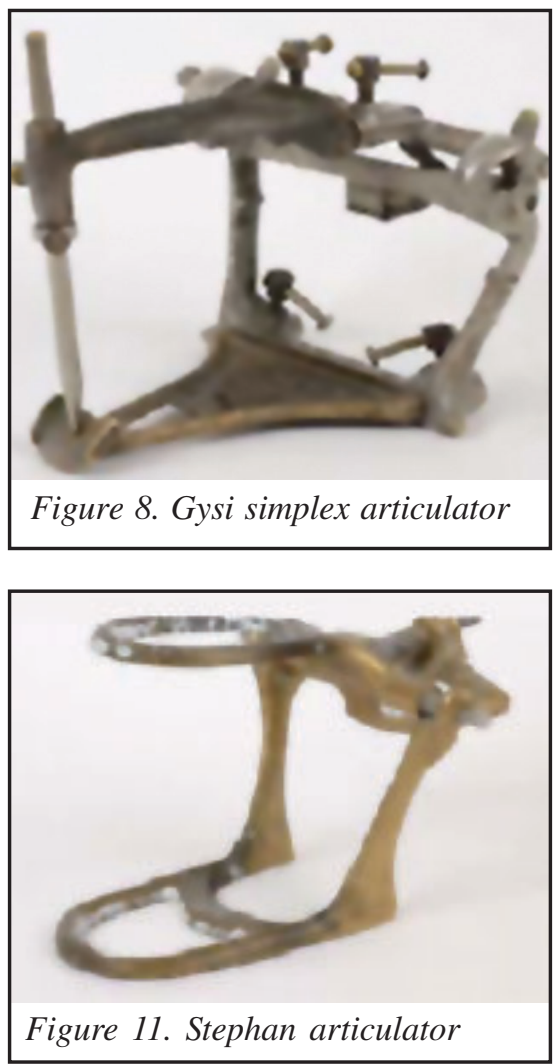


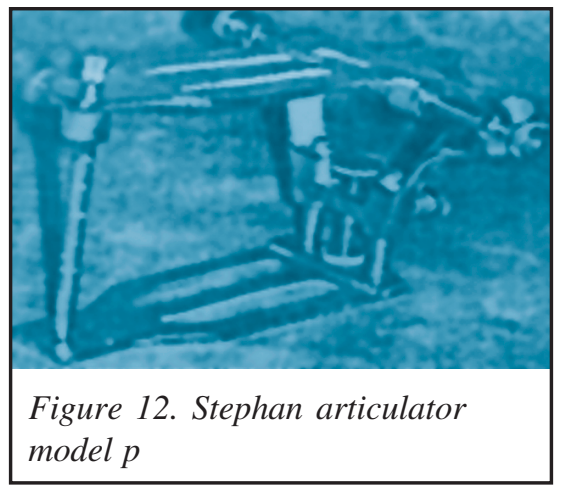

were developed around 1950. The Johnson-Oglesby instrument has limited use and the restorations produced with it may require major adjustments intraorally(43).

The Moyer instrument is a mean value articulator and is non adjustable

\section{Bergstrom articulator (1950) (Figure 15)}

It is a semi-adjustable arcon instrument similar to Hanau $\mathrm{H}$ except condyles on lower and condylar guides on upper frame with curved condylar guides (44).

\section{Transograph in 1952 (Figure 16)}

Nonadjustable split axis instrument designed to allow each condyle axis to function independently of each other. It does'nt accept the condylar axis as an imaginary line through the condyles(45).

\section{Stansberry tripod (Figure 17)}

It is an non-adjustable articulator,accepts facebow transfer, and eccentric relations. It has one mechanical guide located posteriorly and two guides located anteriorly. These guides set by means of

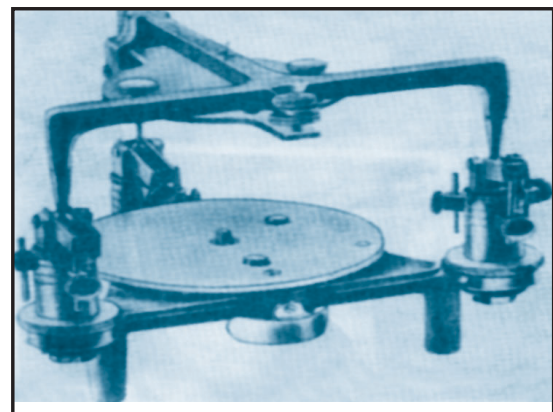

Figure 17. Stansberry tripod

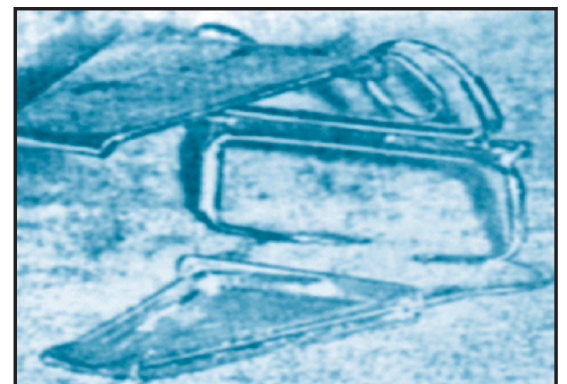

Figure 13. Johnson - Oglesby articulator

interocclusal records. This articulator is based on theory that,within cuspal distances, a straight path from centric to eccentric positions is an acceptable substitute for the actual curved path. Designed primarily for complete denture construction. Provided with a lathe attachment for "milling in" the occlusion of the complete dentures(46).

\section{Kile dentograph in 1955 (Figure 18)}

It is an non-adjustable articulator, custom built for each patient. Vertical dimension of occlusion is established by "Patterson method" (47).
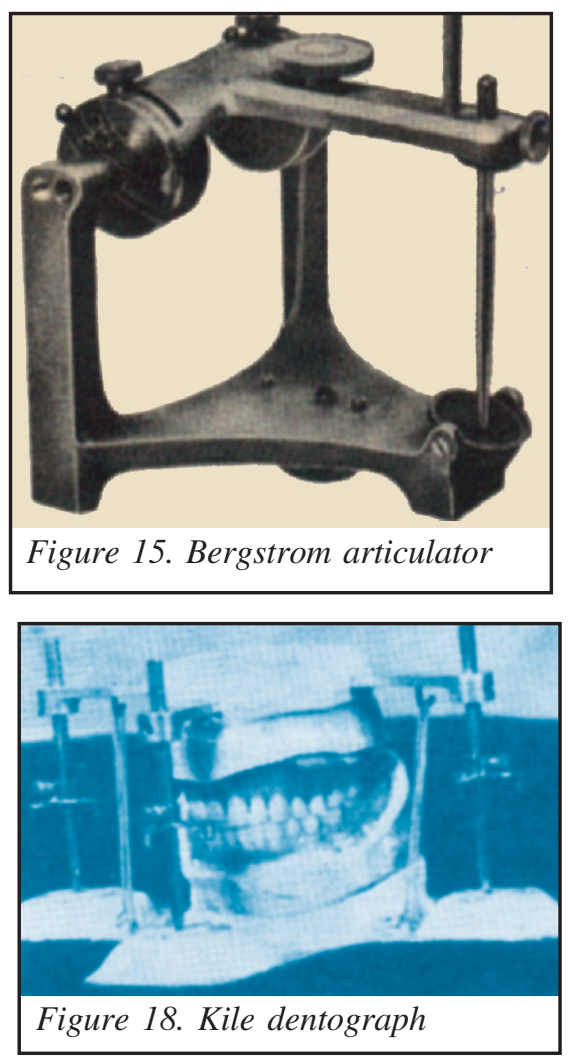

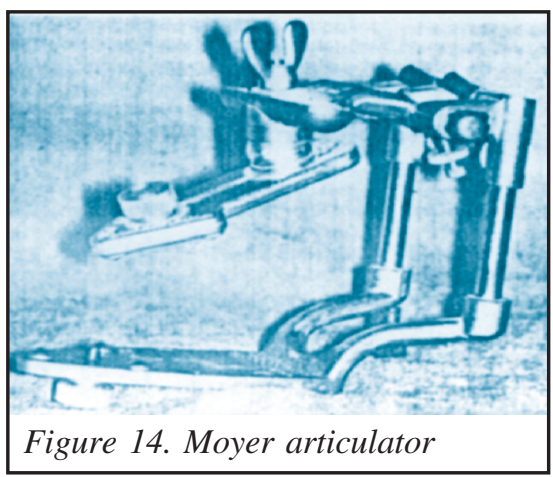

\section{Duplifunctional articulator in 1965 (Figure 19)}

Given by Irish in 1965. It recods mandibular movements. It is served as a three dimensional articulator upon which dentures can be constructed and occlusion can be balanced(47).

\section{Ney articulator in 1960 (Figure 20)}

Designed by de Pietro.It is a fully adjustable, arcon instrument with adjustable intercondylar distance. Maxillary mounting plate has built in split cast device and incisal guide table can be of metal or plastic. It can record gothic arch tracing or pentogram(47).

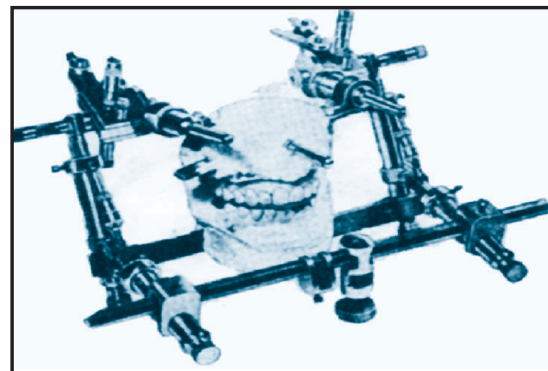

Figure 16. Transograph

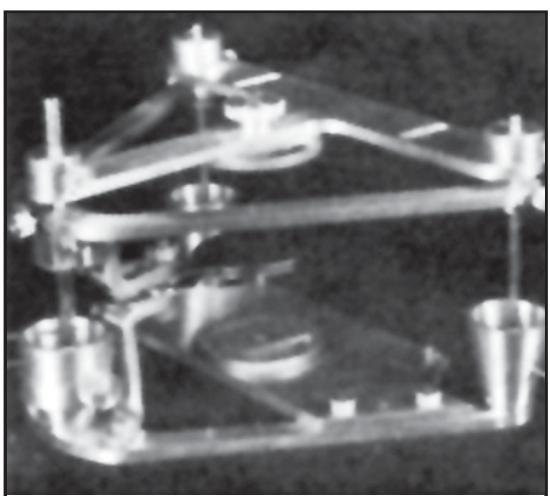

Figure 19. Duplifunctional articulator 


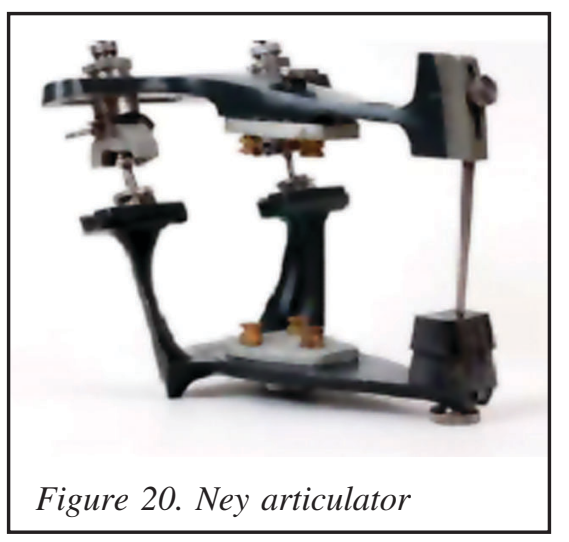

House articulator in 1927 (Figure 21)

Designed by M.M. House, it is a semiadjustable articulator.The casts are mounted arbitrarily. The instrument is adjusted by means of a needles-house "chew in" which employs 4 metal studs in the upper occlusion rim against a lower compound occlusion rim(48).

Diamond-shaped pathways are generated and transferred to articulator as eccentric record (Figure 22).

\section{DISCUSSION}

After having a choice so many articulators and facebows in market today, operator should try to give the most accurate occlusion in prosthesis by recording the jaws relations and jaw movement accurately.

Thorough knowledge of all these instrument is mandatory before using them, as the success or failure of any prosthesis is more dependent on the operator of the articulator than the articulator itself.

Late Carl O Boucher said, "it must be recognized that a person operating a instrument is more important than the instrument".

\section{CONCLUSION}

There have been many school of thoughts regarding which articulator should be used, utility or futility of facebows and many more debates.

The facebow remains controversial because it may or may not be absolute essential to good prosthodontics, as the matrix band

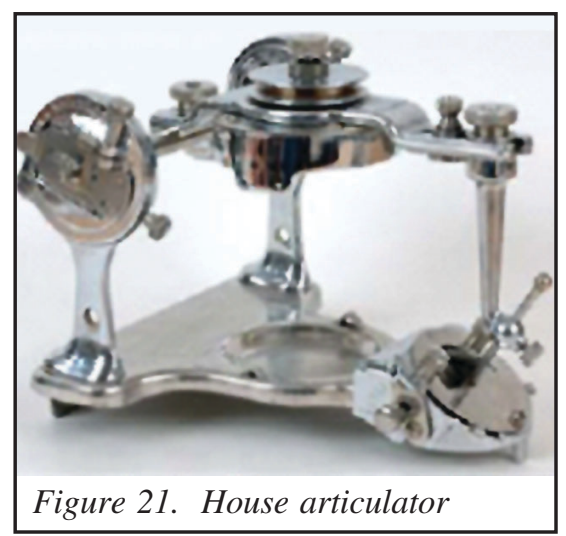

is essential to rood class11 alloy restoration.

No chance should be taken for any kind of error, to increase the physiologic acceptance of prosthesis and to increase the satisfaction of the patient. As we all know," prosthesis fits better in satisfied mouth".

\section{REFERENCES}

1. Winkler S. Essentials of complete denture Prosthodontics, ed 2, IEA 2004, p 142.

2. Glossary of prosthodontic terms,ed7, Mosby, p53.

3. Schweitzer JM. The Transograph and transographic articulation. J Prosthet Dent 1957; 7:595-621.

4. Beck HO. A clinical evaluation of the arcon con-cept of articulation. J Prosthc Dent 1959;9:409-21.

5. Shanahan TJ. Mandibular and articulator movement. J Prosthet Dent 1959; 9:94145.

6. Pruden $\mathrm{WH}$. The role study casts in diagnosis and treatment planning. $J$ Prosthet Dent 1960;10:707-10.

7. Beck HO. Selection of an articulator and jaw registration. J Prosthet Dent 1960; 10:878-87.

8. Shanahan TJ. Mandibular and articulator movement. J Prosthet Dent 1962; 12:67884.

9. Grant AA. Elevation of the incisal guide pin following attachment of casts to articulators 1963;13:664-68.

10. Weinberg LA. An evaluation of basic articula-tors and their concepts. Part-111. Fully adjustable articulators. J Prosthet Dent 1963;13:873-88.

11. Weinberg LA. Arcon principle in the condylar mechanism of adjustable articulators. $J$ Prosthet Dent 1963; 13:263-68.

12. Weinberg LA. An evaluation of basic articulators and their concept. Part 1v. Fully adjustable artic-ulators. $J$ Prosthet Dent 1963;13:1038-54.

13. Lee RL. Jaw movements engraved in

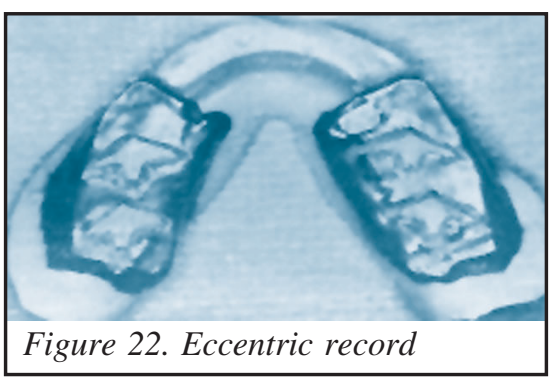

solid plastic for articulator controls. Part 1. Recording apparatus. J Prosthet Dent 1969;22:209-24.

14. Lundeen HC, Wirth CG. Condylar movement patterns engraved in plastic blocks. J Prosthet Dent 1973;30:870-75.

15. Bell LJ, Matich JA. A study of the acceptability of lateral records by the whip-mix articulator. J Prosthet Dent 1977;38:22.

16. Mitchell DL, Wilkie ND. Articulators through the years. Part-1. Up to 1940. J Prosthet Dent 1978;39:330-38.

17. Swanson $\mathrm{KH}$. Complete dentures using the TMJ articulators, J Prosthet Dent 1979;41:497-506.

18. Smith DE. Does one articulator meet the needs of both fixed and removable prosthodontics? J Pros-Thet Dent 1985;54:296-306.

19. Tamaki et al. Reproduction of excursive tooth contact in an articulator with computerized axiography data. J Prosthet Dent 1997;78:373.

20. Korda B, Gartner C. The virtual articulator in dentistry: concept and development, Dent Clin North Am 2002;46:493-506.

21. Stansbery CJ. Futility of the facebow. JADA 1928;15:1467-71.

22. McLean DW. Gnathodynamics in relation in denture prosthesis. JADA 1937;21: 441-45.

23. Kurth LE, Feinstein IK. The hinge axis of the mandible. J Prosthet Dent 1951;4:327.

24. Craddock FW, Symmons HF. Evaluation of the facebow. J Prosthet Dent 1952;2:633-43.

25. Sloane RB. Recording and transferring the mandibular axis. $J$ Prosthet Dent 1952;2:172.

26. Brandrup-Morgsen. The facebow, its significance and application. J Prosthet Dent 1953;3:618.

27. Lazarri JB. Application of Hanau model"c" facebow. J Prosthet Dent 1955;5:626.

28. Sicher $\mathrm{H}$. The biologic significance of hinge axis determination. J Prosthet Dent 1956;6:616.

29. Schallhorn RG. A study of arbitrary centre and kinematic centre of rotation for facebow mounting. $J$ Prosthet Dent 1957; 7:162-69.

30. Brekke CA. Jaw function. Part11, hinge axis, hinge axes. $J$ Prosth Dent 1959;9:936. 
31. Christiansen RL. Rationale of the facebow in maxillary cast mounting. $J$ Prosthet Dent 1959;9:388.

32. Weinberg LA. An evaluation of the face bow mounting. J Prosthet Dent 1961;11:32.

33. Lucia VO. A technique for recording centric relation. $J$ Prosthet Dent 1964; 14:492.

34. Tetereck WR, Lundeen HC. The accuracy of an ear facebow. J Prosthet Dent 1966; 16:1039.

35. Trapozzano VR, Lazzari JB. A study of hinge axis determination. $J$ Prosthet Dent 1967; 17:122.

36. Thorp ER, Smith DE, Nicholls JI. Evaluation of the use of a facebow in complete dentures. J Prosthet Dent 1978;39:5.

37. Wilkie ND. The anterior point of reference. J Prosthet Dent 1979;41:488.

38. Stade E, et al. Esthetic consideration in the use of facebows. J Prosthet Dent 1982;48:253.

39. Palik JF, et al. Accuracy of an earpiece facebow. J Prosthet Dent 1985; 53:800.

40. Heartwell CM, Rahn AO. Syllabus Of Complete Dentures, ed 4, Varghese $1992, p 55$.

41. Winkler S. Essentials of complete denture Prosthodontics, ed 2, IEA 2004, p 144.

42. Heartwell CM, Rahn AO. Syllabus Of Complete Dentures, ed 4, Varghese 1992:p56.

43. Mitchell DL. Wilkie ND. Articulators through the years. Part-11. From 1940. $J$ Prosthet Dent 1978;39:451-58.

44. Winkler S. Essentials of complete denture Prosthodontics, ed 2, IEA 2004:p146.

45. Schweitzer JM. The Transograph and transographic articulation. J Prosthet Dent 1957; 7:595-21.

46. Stansberry CJ. Functional position check bite technic. JADA 1929;16:421-40.

47. Heartwell CM, Rahn AO. Syllabus Of Complete Dentures, ed 4, Varghese 1992: p59.

48. Winkler S. Essentials of complete denture Prosthodontics, ed 2, IEA 2004:p145. 